\title{
Un edificio enterrado ritualmente: la Estructura 1 del montículo J8 del sitio manteño de Japoto, Manabí, Ecuador
}

Un édifice enterré de façon rituelle : la Structure 1 du monticule J8 du site manteño de Japoto, Manabí, Équateur

A Ritually Buried Manteño Building: Structure 1, Platform J8, Japoto, Manabí

Province, Ecuador

\section{Mercedes Guinea}

\section{OpenEdition}

\section{Journals}

Edición electrónica

URL: http://journals.openedition.org/bifea/1728

DOI: 10.4000/bifea. 1728

ISSN: 2076-5827

Editor

Institut Français d'Études Andines

Edición impresa

Fecha de publicación: 1 diciembre 2010

Paginación: 503-530

ISSN: 0303-7495

Referencia electrónica

Mercedes Guinea, « Un edificio enterrado ritualmente: la Estructura 1 del montículo J8 del sitio manteño de Japoto, Manabí, Ecuador », Bulletin de l'Institut français d'études andines [En línea], 39 (3) I 2010, Publicado el 01 junio 2011, consultado el 08 diciembre 2020. URL : http:// journals.openedition.org/bifea/1728; DOI : https://doi.org/10.4000/bifea.1728

\section{(c) (†) $\odot$}

Les contenus du Bulletin de l'Institut français d'études andines sont mis à disposition selon les termes de la licence Creative Commons Attribution - Pas d'Utilisation Commerciale - Pas de Modification 4.0 International. 


\title{
Un edificio enterrado ritualmente: la Estructura 1 del montículo $\mathbf{3 8}$ del sitio manteño de Japoto, Manabí, Ecuador
}

\author{
Mercedes Guinea*
}

\begin{abstract}
Resumen
El año 2007, durante los trabajos de campo del Proyecto Manabí Central en Japoto, se localizó una estructura que se había conservado, a pesar de la fragilidad de sus materiales de construcción, ya que fue enterrada intencionalmente debajo de toneladas de tierra y cascajo traído del estero cercano, visualizándose en el terreno como uno más de los montículos habitacionales del sitio. Un primer sondeo del montículo J8 reveló algunos de los elementos arquitectónicos de la E1, conformada básicamente por una plataforma baja encima de la cual se encontró un recinto rectangular delimitado por un murete escalonado, una pared con un zócalo adosado y un grueso muro, quedando abierto al oeste por uno de su lados largos. En este artículo se brindan los resultados de la campaña arqueológica del 2008, su valoración e interpretación preliminar.
\end{abstract}

Palabras clave: arqueología, Ecuador, Japoto, arquitectura de tierra, manteño, entierro de templos

\section{Un édifice enterré de façon rituelle : la Structure 1 du monticule J8 du site manteño de Japoto, Manabí, Équateur}

\section{Résumé}

En 2007, les fouilles du Projet Manabí Central sur le site de Japoto, ont permis de localiser une structure qui avait été conservée, malgré la fragilité de ses matériaux de construction, grâce à un enterrement volontaire sous des tonnes de terre et de gravier provenant de l'estuaire tout proche. Cette structure fut identifiée comme un nouveau monticule d'habitation du site. Un premier sondage du monticule J8 a permis de mettre à jour quelques éléments architectoniques de la Structure 1, qui se compose

Profesora Titular, Universidad Complutense de Madrid, Departamento de Historia de América II, Facultad de Geografía e Historia: C/ Profesor Aranguren s/n - 28040 Madrid, España. E-mail: guinea@ghis.ucm.es 
essentiellement d'une plate-forme basse au sommet de laquelle se trouve un espace rectangulaire délimité par un muret échelonné, une paroi avec une plinthe adossée et un mur très épais, restant ouvert à l'Ouest sur l'une de ses longueurs. Cet article offre les résultats de la campagne de fouille archéologique de 2008, leur examen ainsi qu'une interprétation préliminaire.

Mots clés : archéologie, Équateur, Japoto, architecture de terre, Manteño, enterrement de temples

\title{
A Ritually Buried Manteño Building: Structure 1, Platform J8, Japoto, Manabí Province, Ecuador
}

\begin{abstract}
During the 2007 field season of the Central Manabí Archaeological Project has been discovered a structure which, despite the fragility of its construction materials, was preserved by ritual entombment under tons of dirt and coarse gravel brought from a nearby streambed. The first test pit in Platform J8 exposed some of the architectural features of Structure 1. Excavation revealed a low platform on top of which was built a rectangular enclosure defined by a stepped wall, another wall with a buttressed base, and a very thick wall, leaving the long west side open. In this paper the results of the 2008 field work are presented, including a preliminary evaluation and interpretation of the structure.
\end{abstract}

Key words: Archaeology, Ecuador, Japoto, earthen architecture, Manteño, entombment of temples

\section{INTRODUCCIÓN}

El año 2007, cuando apenas quedaban siete días para la finalización de los trabajos de campo que, durante cuatro años, venían llevando a cabo los miembros del Proyecto Manabí Central en el yacimiento arqueológico de Japoto, el equipo de la Universidad Complutense de Madrid, dirigido por la autora, localizó una estructura de tierra, adobe, quincha1 madera y caña. Esta estructura se había conservado, a pesar de la fragilidad de sus materiales de construcción, debido a que fue enterrada intencionalmente debajo de toneladas de tierra y cascajo traído del estero cercano, visualizándose en el terreno como uno más de los montículos habitacionales del yacimiento. Como la mayor parte de ellos, ha sido tractorado, sembrado, y huaqueado repetidamente sin que, afortunadamente, la estructura que ocultaba hubiera sido gravemente afectada hasta el momento (fig. 1). El

1 La voz quechua quincha tiene un uso doble que puede dar lugar a equívocos. Por un lado, se denomina así a todo un sistema constructivo que consiste fundamentalmente en una estructura vertical de madera con un entramado horizontal de caña picada cubierta por uno o dos lados con una mezcla de arcilla, arena, paja seca y agua. Por otro lado, el término se utiliza para referirse solo a la mezcla con la se que cubre la caña, la cual puede ser empleada para otros usos. En el Manabí actual, quincha es arcilla, arena, paja seca y agua mezclada con los pies y enquinchar el proceso de cubrir las paredes de caña con esta mezcla. Con este último significado es con el que empleo el término en el texto. 


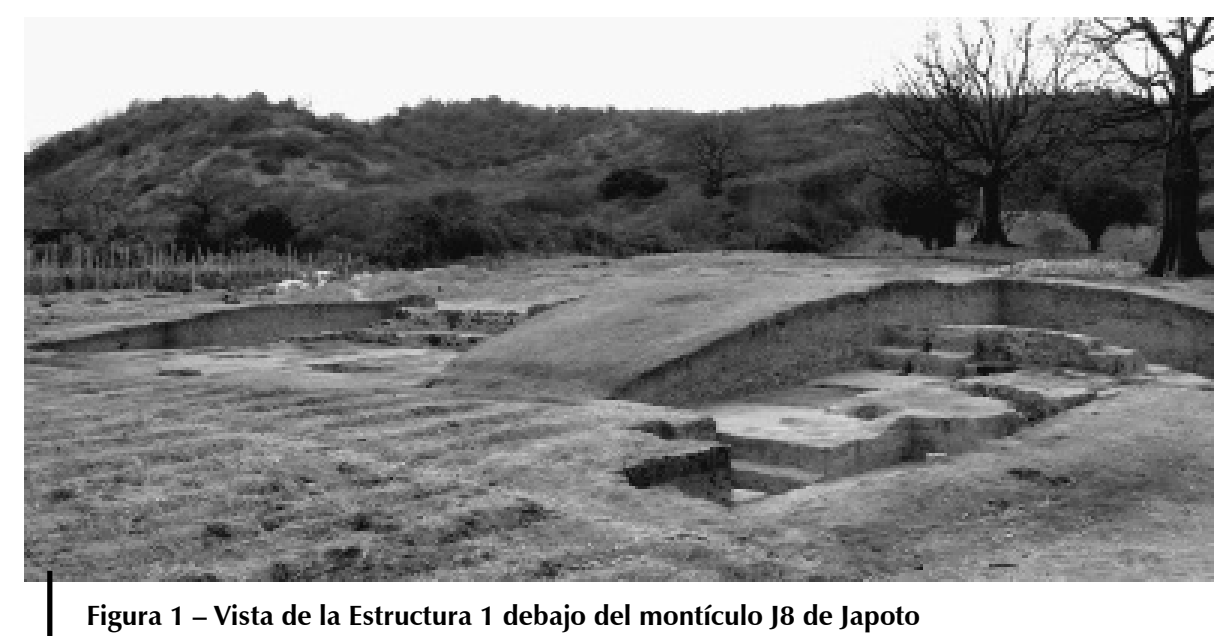

Figura 1 - Vista de la Estructura 1 debajo del montículo J8 de Japoto

Foto: M. Guinea

afortunado hallazgo obligó a prorrogar los trabajos de campo una temporada más (junio-julio de 2008) con el objetivo principal de excavar dicha estructura (E1), cuyos resultados preliminares son el objeto de este artículo.

Tanto los materiales constructivos de la Estructura 1, como su estado de conservación son excepcionales en la costa del Ecuador donde la arquitectura de tierra está poco documentada, lo cual no es de extrañar dadas las condiciones climáticas y lo sensibles que son a las lluvias estos materiales. No obstante, se encuentran montículos de tierra (tolas) de muy diversas alturas y funciones en todos los períodos prehispánicos. Muchos de ellos sirvieron como basamentos de edificios de carácter público o religioso, algunos solamente conocidos a través de las representaciones cerámicas. Ya desde principios del tercer milenio a. C. tenemos en el sitio Valdivia de Real Alto montículos ceremoniales de tierra en cuya cima se levantaron edificios especiales de bahareque2, que recibían reconstrucciones periódicas en las cuales iban quedando encapsulados los edificios anteriores (Marcos, 1988: 31-41). En los niveles del Formativo Tardío de Salango, encontramos un proceso similar de sucesivas reconstrucciones de un recinto ceremonial, conformando una plataforma cada vez mayor (Lunniss, 2007). Encontramos modelos cerámicos de casas o templos, que se levantan sobre plataformas, en las culturas Chorrera, Tolita y Jama Coaque. Por su parte, Jijón y Caamaño (1997 [1952]: 104-105) nos ha dejado planos de grandes montículos de base rectangular, pertenecientes a la culturas Bahía y Manteña, coronados por

2 La voz taina bahareque tiene el mismo uso equívoco que la de quincha y se refiere también a un sistema constructivo de la familia de los entramados, aunque difiere de la quincha en algunos aspectos técnicos, como el embutido del barro. En puridad, los sistemas constructivos bahareque y quincha solo son sinónimos cuando el primero es de encañado simple, sin embutido. No obstante, reciben uno u otro nombre dependiendo de las localidades, al igual que la mezcla de arcilla, arena, paja y agua, que cubre las cañas. 
edificios de cimientos de piedra. Más ocasional es el hallazgo de arquitectura de quincha como en la Estructura 1. Sin embargo, además del citado bahareque de Real Alto, el encuentro en la superficie del suelo de las estructuras mánteñas de Agua Blanca de grandes cantidades de baharaque 3 quemado con impresiones de cañas y palos lleva a suponer a McEvan (2003: 262-269) que la parte alta de las paredes estaría fabricada de este material. Igualmente, encuentra indicios de que todo el exterior de los edificios estaría enlucido en el mismo barro. Incluso localiza en la esquina NE de uno de ellos los restos de una fachada modelada en bahareque. Menos frecuente que la construcción de plataformas de tierra o el hallazgo de restos de quincha (o bahareque), generalmente quemado, son las evidencias del uso de adobes en la costa del Ecuador. McEvan (2003: 266) en Agua Blanca y Marcos (1981: 58-59) en La Loma de los Cangrejitos los han encontrado formando parte de refuerzos estructurales de las plataformas de tierra sobre las que se levantaban las edificaciones. Hasta el momento, parece ser que la Estructura 1 de Japoto es la primera conocida en la costa ecuatoriana en la que los adobes forman parte de la arquitectura del edificio.

En otro orden de cosas, la excepcionalidad de los materiales de construcción, la ausencia de restos de actividad y las propias circunstancias de su entierro nos llevan a proponer una función ceremonial para la E1. El «entierro ritual» de edificios de carácter sagrado es una actividad de amplia tradición andina, que hinca sus raíces en la «Tradición Mito-Kotosh» (Felmand, 1992: 73-74), documentada en numerosos sitios del norte y centro del Perú desde el Arcaico Tardío como Caral (Shady \& López, 2003) o Cerro Lampay (Vega-Centeno, 2005), continuando con fuerza en algunos lugares de la costa norte hasta la llegada de los españoles, mientras que en otros parece desaparecer a partir de Wari (Shimada, 1995: 28). Generalmente, aunque no siempre, este entierro supone la construcción de otro de similares características encima, lo que hace que algunos autores prefieran Ilamarlo «renovación de templos» (Shimada et al., 2004: 535). Creo que dentro de esta renovación de templos se pueden enmarcar los ejemplos de superposición de plataformas en los sitios formativos ecuatorianos de Real Alto y Salango citados más arriba.

Estos edificios sagrados se consideran repositorios del poder sobrenatural y por lo tanto deben de ser alimentados con ofrendas para mantenerlos vivos y «matados» ritualmente para remover este peligroso poder antes de enterrarlos. Todo el proceso lleva asociado una serie de actividades rituales de difícil interpretación en la excavaciones arqueológicas, entre otras cosas porque pudieron ser fácilmente destruidos en el proceso de construcción del nuevo edificio. Las ofrendas de fundación y dedicación de una casa o un templo son generalmente mejor reconocidas, quizás por tener un referente más próximo en nuestra propia cultura. No ocurre lo mismo con las ofrendas o depósitos motivados por el abandono y cancelación de su función o las dedicadas a su alimentación periódica para el mantenimiento de su poder. Incluso, los materiales de construcción y tapado de estas estructuras pueden tener componentes o significación especial. La

3 En este caso McEvan define bahareque como una mezcla de barro y arcilla. 
construcción de un edificio para uso ritual puede ser a su vez una actividad ritualizada (Vega-Centeno, 2007).

\section{EL SITIO DE JAPOTO}

El sitio de Japoto citado por primera vez por Estrada (1957: 33; 1962: 28) como San Jacinto, es el único sitio con montículos que se ha preservado hasta la actualidad en la costa de Manabí y uno de los focos de atención del Proyecto Manabí Central, desarrollado desde el año 2003 por la Misión Francesa en el Ecuador en colaboración con la Universidad Complutense y el Cantón de Sucre (ver Bouchard en este mismo volumen).

El yacimiento arqueológico se encuentra en las proximidades de la parroquia de San Jacinto, a 28 km de Bahía de Caráquez, situado $2 \mathrm{~km}$ hacia el interior desde la línea de la playa y cerca de la margen derecha de la desembocadura del río Portoviejo4. Los trabajos de prospección estiman en unas 60-80 hectáreas el área por la que se dispersan los restos arqueológicos, actualmente en un proceso de destrucción muy avanzado por la construcción y la expansión de las salinas y trabajos agrícolas mecanizados. Por razones operativas, las excavaciones del citado proyecto se han llevado a cabo dentro de una finca privada (19,7 ha) en la que aún se reconocen 60 montículos artificiales y restos de otros muchos ya destruidos. Las intervenciones arqueológicas durante las campañas 2004-2007 se han concentrado en su área NE en el que los montículos visibles, con una altura entre 1 y $5 \mathrm{~m}$, tienen plantas rectangulares, ovaladas o redondeadas, alcanzando los más grandes hasta $60 \mathrm{~m}$ de largo por 20 de ancho. De los nueve excavados hasta el momento, siete parecen tener funciones habitacionales (Guinea, 2006a; 2006b; Touchard, 2006), uno funerarias (Delabarde, 2006) y el restante es el montículo J8 que cubre la Estructura 1.

Los materiales recuperados en todos ellos están en proceso de análisis, pero los primeros resultados de los estudios cerámicos (Stothert, 2006) y las fechas radiocarbónicas, entre AD 617-1454, confirman su pertenencia a los dos períodos de la cultura manteña, aparentemente con un mayor grado de ocupación del sitio en el temprano5. En el caso concreto de la Estructura 1 del j8 la fechas obtenidas en la campaña de 2007 muestran un rango entre cal AD 1021 y AD 1278, siendo la más fiable y de más alta probabilidad (2 sigma 0,993396) la obtenida directamente de carbón sobre el piso cal AD 1021: cal AD 1186.

4 GPS $0^{\circ} 17^{\prime} 37^{\prime \prime}$ sur; $80^{\circ} 30^{\prime} 36^{\prime \prime}$ '.

5 Más información sobre el Proyecto Manabí y sus resultados en la página web: http://macgalatea.sip. ucm.es/web/infoProyecto/manabicentral.php 


\section{EL MONTÍCULO J8}

Como hemos dicho más arriba, la campaña arqueológica de 2007 cerró el primer ciclo de las excavaciones del Proyecto Manabí en la zona, por lo que se decidió la intervención en el montículo J8 ya que este presentaba una forma exterior diferente al resto de los excavados en el yacimiento (fig. 2). Parece estar conformado por dos montículos superpuestos parcialmente, lo que le otorga una cierta singularidad. Este elemento sugiere una posible «tola con rampa» o la reocupación parcial de un montículo anterior. Con el fin de confirmar o rechazar estas hipótesis, se decidió realizar un primer sondeo que dio como resultado el hallazgo de una estructura enterrada (E1), de la que se pudo obtener una primera evaluación de tamaño, principales elementos arquitectónicos y materiales empleados en su construcción. A partir de esta, se planificó su excavación en la campaña 2008 cuyos resultados preliminares se presentan a continuación.

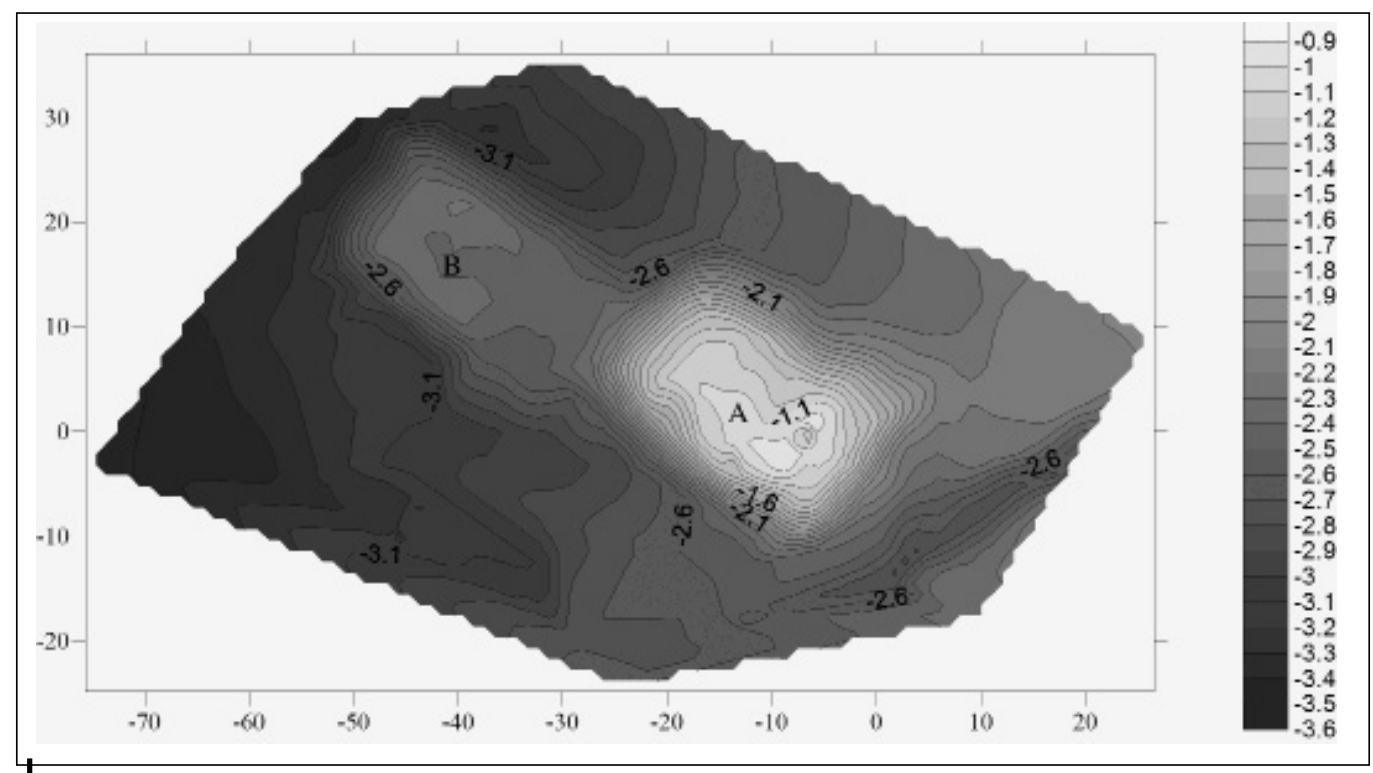

Figura 2 - Topografía del montículo J8 de Japoto

Levantamiento: G. Clément

El montículo J8, cuyo eje largo orientado $20^{\circ} \mathrm{E}$ mide $60 \mathrm{~m}$, se compone de dos cuerpos unidos, A y $\mathrm{B}$, que se diferencian en sus alturas sobre el terreno y en su forma general, especialmente en la proporción entre el área de la base y la de la cima. El extremo norte, lo ocupa una plataforma (fig. 2 B), de base y cima rectangulares, con ángulos bien marcados. Mide $29 \times 21 \mathrm{~m}$ en la base, $21 \times 12 \mathrm{~m}$ en la cima y tiene en su extremo norte $80 \mathrm{~cm}$ de altura máxima sobre el terreno circundante, altura que va disminuyendo hacia el sur y llega a ser la mitad en su confluencia con el segundo cuerpo del montículo, A, al que se encuentra adosado. 
Esta forma, de base rectangular angulosa y cima plana solo se da, en el área de la finca objeto de los trabajos arqueológicos, en otros dos montículos, J1 y J2, los cuales son colindantes con el J8. Por su parte, el otro cuerpo (fig. 2A) ocupa algo más de la mitad sur del J8. Su área en la base es de 31 x 24 m y de 18 × 8,5 m en la cima. La altura sobre el terreno circundante es algo irregular: 1,32 m por el lado $\mathrm{E}$, 1,60 $\mathrm{m}$ por el $\mathrm{W}, 1,30 \mathrm{~m}$ por el $\mathrm{S}$ y de 1,20 $\mathrm{m}$ al $\mathrm{N}$, sobre la plataforma. A pesar de que su base y cima son también rectangulares, la diferencia entre ambas áreas y su mayor altura le dan cierta forma tronco piramidal con las esquinas redondeadas, el aspecto más común en los montículos del yacimiento.

\section{1. Excavaciones arqueológicas}

La intervención arqueológica del montículo J8 en la campaña 2007, una vez detectada la presencia de la Estructura 1 bajo la tola, consistió en unos pozos de sondeo realizados a lo largo de dos ejes que la cortaban de forma ortogonal orientados $20^{\circ} \mathrm{E}$, a través de los cuales se pudo hacer una primera estimación del tamaño y situación de la Estructura 1. Como dijimos con anterioridad, en la campaña 2008 uno de los objetivos prioritarios de las excavaciones del proyecto fue la recuperación de la máxima información posible de la Estructura 1, no solo por la importancia del hallazgo para la interpretación del sitio, sino también porque, al estar en un terreno agrícola sin protección ninguna, el montículo está siendo tractorado y regado artificialmente de forma repetida con el consiguiente deterioro y pérdida de información, ya que en algunos lugares la estructura está a escasos centímetros de la superficie del terreno.

Con la información obtenida por lo sondeos del año 2007 (Guinea, 2008), se planeó una excavación en un área del sector del montículo J8 (mitad W del cuerpo A) que cubría la Estructura I, con la finalidad de poder establecer la naturaleza de la estructura o estructuras arquitectónicas, así como para la recuperación de los contextos asociados, dejando como testigo $6 \mathrm{~m}$ en su parte centro sur. Para su control, el área de excavación $\left(376 \mathrm{~m}^{2}\right)$ se dividió en 4 unidades cuadriculadas en subunidades de $2 \times 2 \mathrm{~m}$. Estas unidades se rebajaron hasta los niveles de la Estructura 1, rescatando las evidencias de su proceso de tapado y efectuando un decapado de sus superficies y rasgos asociados (fig. 3). En algunas de las subunidades se realizaron cortes y sondeos por debajo de su nivel. También se tomaron numerosas muestras de los materiales constructivos para distintos análisis periciales, termoluminiscencia y $\mathrm{C14}$, de las que solo disponemos de algunos resultados. Paralelamente a la excavación principal, se rebajaron los niveles superiores del cuadrante NE de la tola hasta el nivel del piso de la Estructura 1, evidenciando únicamente material de relleno. No se hizo lo mismo con el cuadrante SE, ya que se apreciaron signos de la posible existencia de otra estructura o de elementos constructivos del montículo que demandaban una excavación más detenida para la recuperación de la información.

En el cuerpo B, se planeó un corte E/W, que no pudo concluirse por falta de tiempo. Los $6 \times 2 \mathrm{~m}$ abiertos de la trinchera de sondeo y las profundidades alcanzadas 


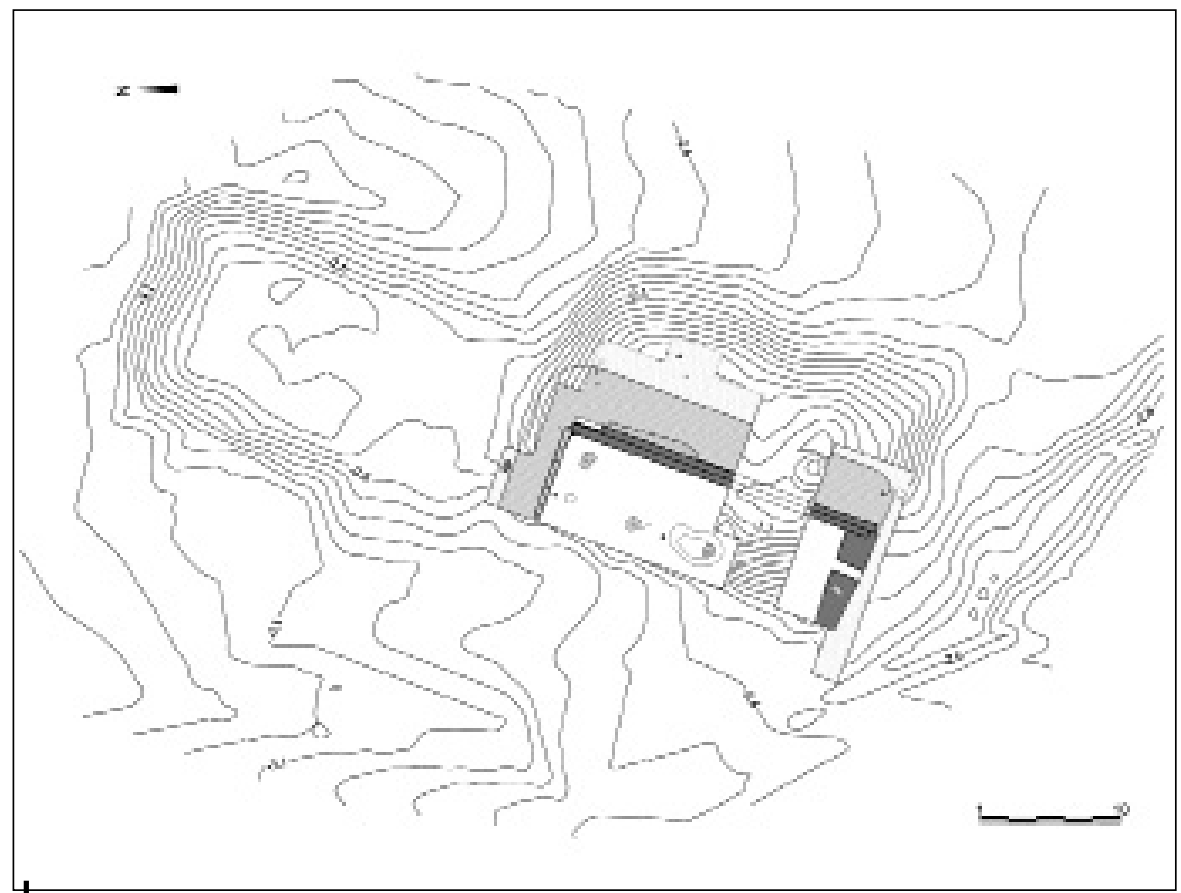

Figura 3 - Área de excavación y localización de la Estructura 1 del montículo J8

Dibujo: N. Simonelli. Original: M. Guinea

$(1,10 \mathrm{~m})$, solo evidenciaron material de relleno. Fuera ya del área cubierta por el montículo J8, se abrió un pozo de sondeo (U2/A7) a 4,5 m, dirección W, del final del piso de la Estructura 1, que tampoco se alcanzó a completar y no aportó mayor información.

\section{2. Estratigrafía}

La estratigrafía del sector excavado revela que la construcción del montículo se enmarca dentro de un proceso de tapado o enterramiento de un edificio del cual forma parte la Estructura 1 y, aunque las capas presentan algunas variaciones en el espesor y densidad de algunos de sus componentes, son lo bastante uniformes en el conjunto del montículo como para poder describir el proceso, tomando como referencia uno de los perfiles E/W (fig. 4). Este perfil presenta una primera capa de tierra vegetal seguida de cuatro de relleno (tierra compacta, cascajo suelto, cascajo y arcilla con inclusiones y cascajo más compacto), un nivel de incendio y finalmente la estructura que cubren. Los elementos arquitectónicos que se observan en el perfil son: un murete escalonado de adobes, el talud reforzado de la plataforma roto en su parte superior, un piso de quincha cocida y la plataforma 


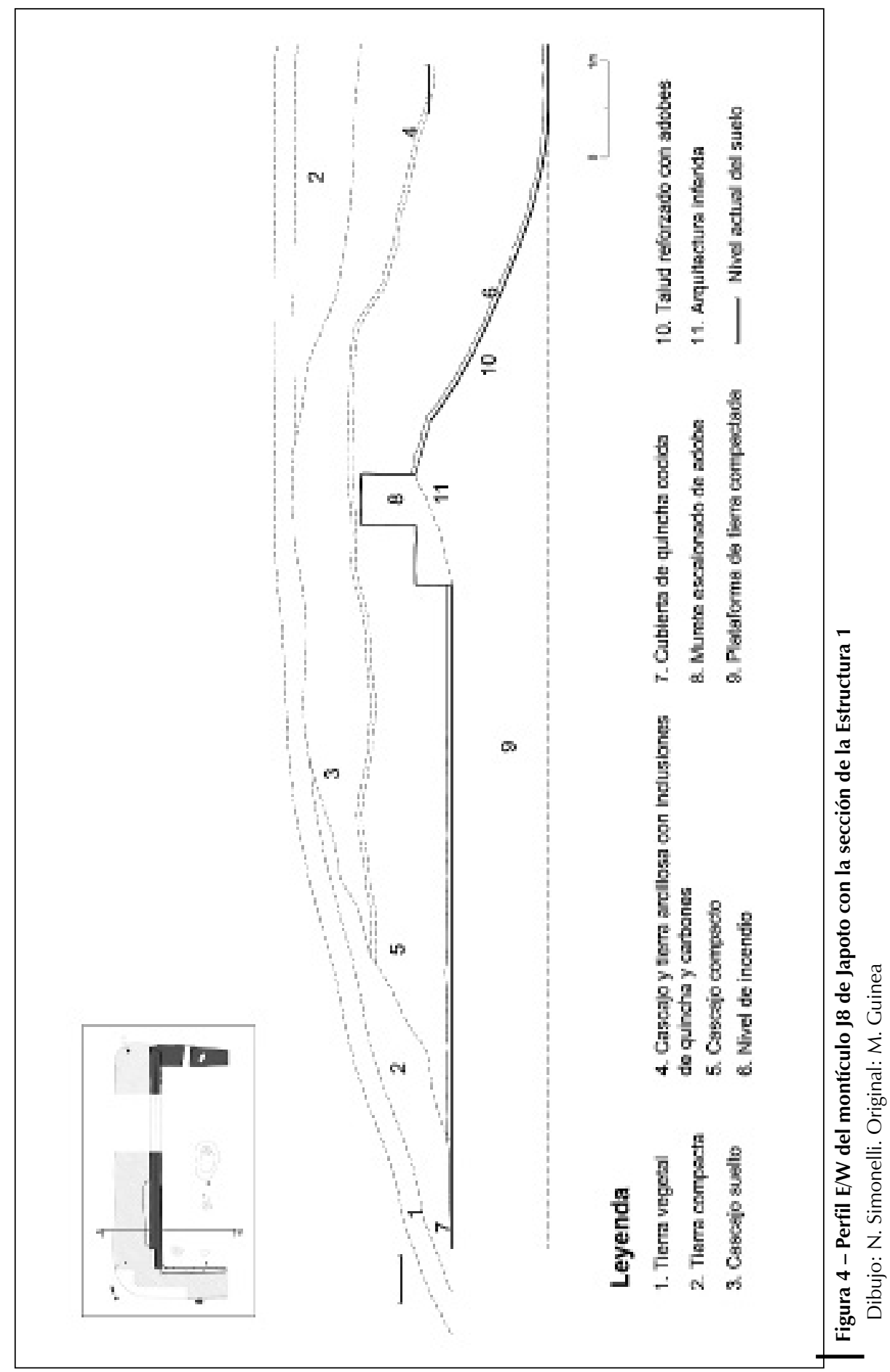


de tierra compactada sobre la que se levanta la estructura. Se distinguen tres secuencias constructivas de muy distinta naturaleza: la construcción del edificio, de la que me ocuparé detenidamente en el siguiente apartado, el tapado del edificio y las remodelaciones y rellenos para la formación del montículo tal y como aparece actualmente en el terreno.

El «entierro del edificio» se llevó a cabo cubriendo la estructura con dos capas de cascajo6, sin material cultural más que ocasionales fragmentos cerámicos, separadas por una capa intermedia con restos de materiales de construcción. La primera de estas capas, en su contacto con el piso de la estructura, envolvió un área continua de $10 \mathrm{~m}^{2}$ y otras dos próximas de menor tamaño (fig. 5, R17) en la que se agrupaban adobes y fragmentos de grandes planchas de quincha, ambos con restos de enlucido de quincha cocida en uno o dos de sus lados. Parecían proceder del desmonte de alguno de los elementos arquitectónicos del edificio y fueron colocados sobre el primer escalón del murete y el piso cuando ya los cubría una ligera capa de cascajo. Un rasgo similar (fig. 5, R30) corre paralelo al muro sur, donde adobes de distintos materiales, enlucidos en ocasiones, se localizan a distintas alturas. A su vez, sobre el talud E de la plataforma se encuentran dispersos algunos adobes rotos o enteros, también revueltos con esta primera capa. Una vez cubierta toda la estructura de cascajo se procedió a una especie de «sellado»con una capa de cascajo mezclado con restos de materiales constructivos que incluyen fragmentos, no muy grandes, de quincha cocida y adobes, algunos carbones y tierra arcillosa amarillenta. Sobre éste se depositó una segunda capa de cascajo más suelto.

Para darle al cuerpo sur del montículo J8 su aspecto actual, se añadió sobre el cascajo una última capa de tierra arcillosa compacta color amarillo claro con esporádicos fragmentos cerámicos y una potencia máxima de $75 \mathrm{~cm}$ en los extremos de la estructura. Es similar a las capas sucesivas de relleno que se encuentran en el resto de los montículos del yacimiento. No es posible saber si el montículo J8, en su apariencia actual, estaba terminado para sus constructores. La singularidad de su forma, que fue la que nos condujo a su excavación, no se explica en su totalidad por el tapado de la estructura. Cabe la posibilidad, muy difícil de probar, de que estuviera en un estadio de construcción parcial, cuyo objetivo final fuera rellenar y subir el cuerpo norte (fig. 2 B) hasta alcanzar la altura del sur (fig. 2A), con lo que el resultado final sería un montículo de base rectangular de la misma forma y tamaño que el colindante $\mathbf{J 1}$ con el que forma un ángulo recto perfecto, dejando un amplia plaza entre los dos. Finalmente, todo lo cubre una capa de tierra vegetal que ha sido removida y arada con regularidad, al menos en los últimos cinco años, conteniendo los restos de alimentación habituales en el yacimiento y fragmentos de cerámica fácilmente identificable como manteña.

6 Este cascajo, sedimento de piedras blanquecinas deleznables, de pequeño tamaño en general, se encuentra en un estero cercano que rodea la finca. En ocasiones incluye nódulos irregulares más grandes de arcillolita que, por el peso, ruedan hacia la parte baja del declive de las capas. 


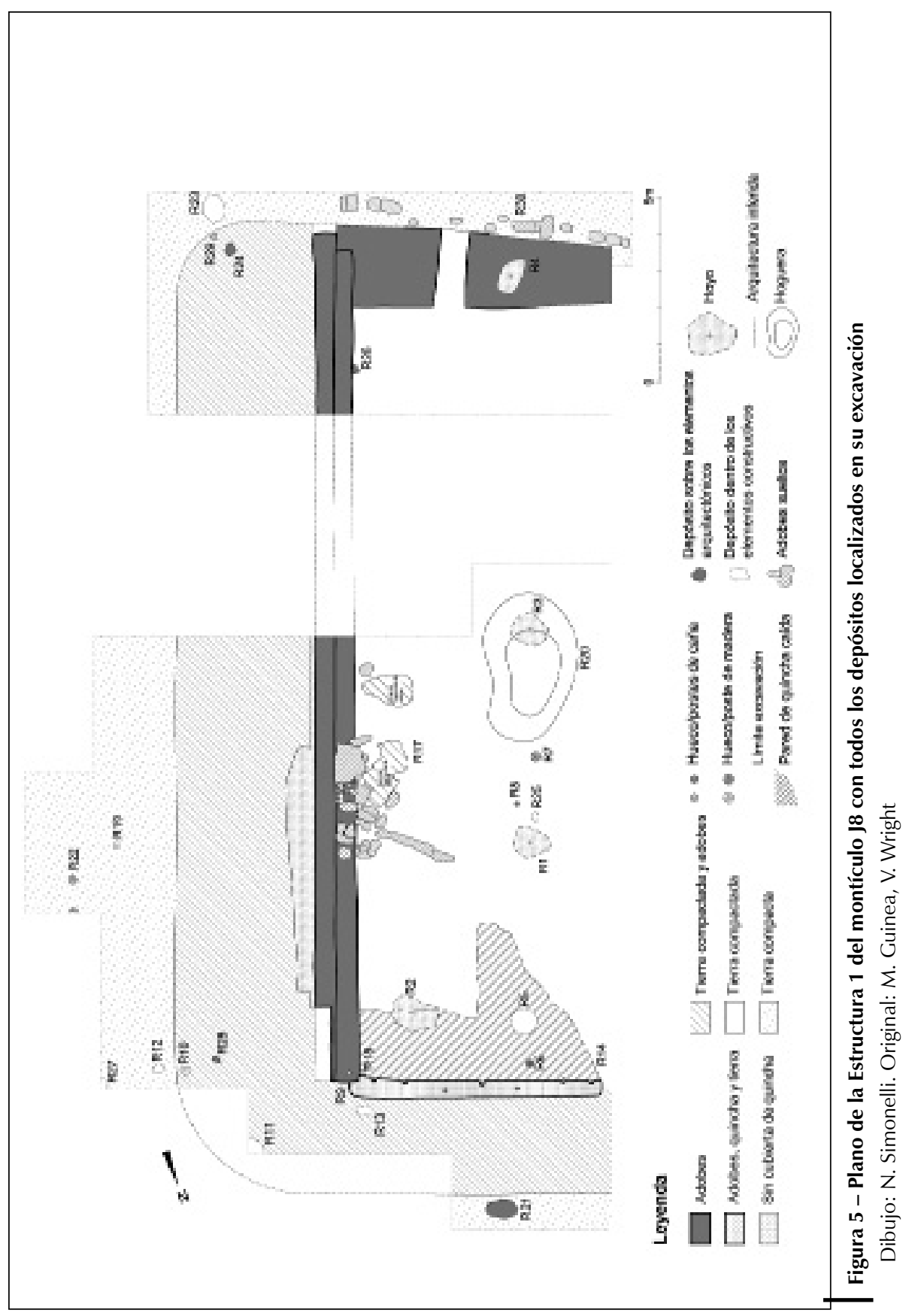




\section{ANÁLISIS ARQUITECTÓNICO DE LA ESTRUCTURA 1 DEL MONTÍCULO j8}

Los trabajos de campo de 2008 han servido para confirmar y completar la información sobre los elementos arquitectónicos identificados en la campaña anterior (Guinea, 2008) a la vez que para localizar otros que han aumentado en gran medida nuestro conocimiento acerca de la Estructura 1 del montículo J8. Lamentablemente, a pesar del esfuerzo de todos, obreros y miembros del proyecto, que trabajamos bajo la presión de la muy probable destrucción de las evidencias que no pudiéramos recuperar, no fue posible con el tiempo y los medios disponibles finalizar la excavación completa de la Estructura 1. Faltaron por revelarse en su totalidad algunos de los elementos arquitectónicos que la conformaron y mucha de la información que sería necesaria para la reconstrucción de todas sus fases y sistemas de construcción. En el estado actual de la investigación no es posible determinar si lo que estamos Ilamando Estructura 1 es un edificio exento o forma parte de otro de mayor complejidad.

\section{1. Morfología}

La Estructura 1 (fig. 6) se presenta como una plataforma rectangular de $1 \mathrm{~m}$ de grosor, reforzada en talud en sus vertientes $\mathrm{E}$ y $\mathrm{N}$, encima de la cual se encuentra un recinto ${ }^{7}$ orientado $20^{\circ} \mathrm{E}$. Este se encuentra delimitado por un murete escalonado al $\mathrm{E}$, una pared con un zócalo adosado al $\mathrm{N}$ y un muro de gran grosor al $\mathrm{S}$, en el cual se abre un vano de acceso en rampa, quedando aparentemente abierto el recinto por su lado $\mathrm{W}^{8}$. Su espacio interior, 20,80 x 6,75 m, queda bien delimitado por los volúmenes que lo rodean y un piso de quincha cocida. Sin embargo, el límite $\mathrm{W}$ de la plataforma artificial se encuentra fuera del área excavada, faltando por determinar si es un elemento exento o se encuentra adosada a otro montículo natural o artificial. En el piso del recinto y en la base del talud de la vertiente $E$ de la plataforma, hay huellas de los soportes de la techumbre, cuyos restos quemados o calcinados cubrirían la mayor parte de la estructura. El talud E de refuerzo de la plataforma, que alcanza la cabecera del murete y cubre su paramento exterior, presenta una amplia rotura en la que puede haberse encajado algún otro elemento arquitectónico, desmontado antes del incendio de la estructura, al que pudieran pertenecer algunos de los restos de construcción que se encontraban sobre el piso (fig. 5, R17 y R30).

7 Hablamos de un único recinto, ya que sabemos por los sondeos que el murete aparece bajo el testigo no excavado, aunque no hay que descartar que pueda existir algún elemento divisorio sobre el piso.

8 Es posible que una fuerte inclinación de la techumbre funcionara a modo de cerramiento por este lado. 


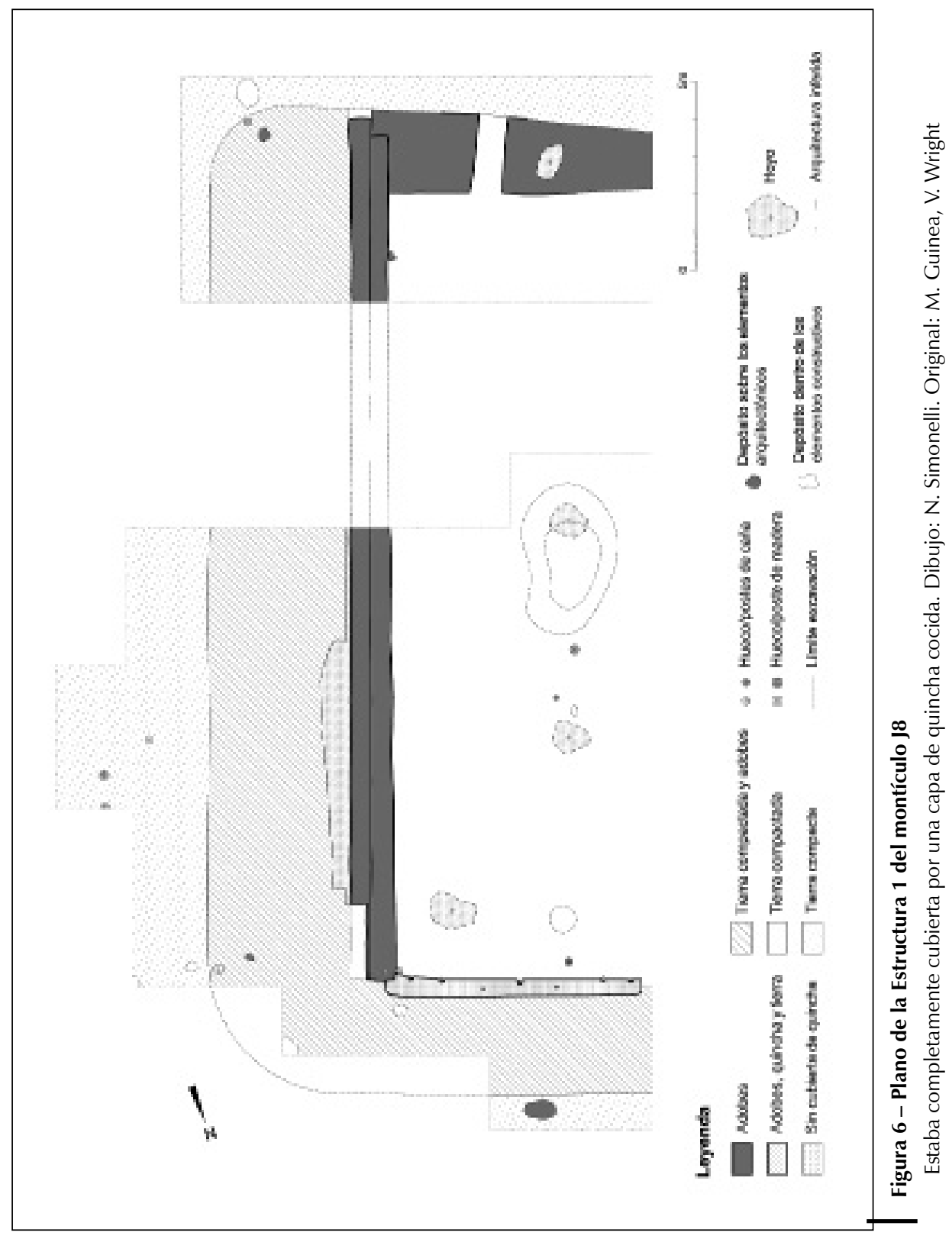




\section{2. Elementos arquitectónicos, técnicas y materiales de construcción}

Un aspecto destacable de la Estructura 1 es la variedad de sistemas constructivos de arquitectura de tierra que combina en un solo recinto de morfología simple: apisonado, adobe y quincha. Esto hace muy difícil una descripción general, así que incluimos los detalles en la presentación de los distintos elementos constructivos.

\section{2. 1. Plataforma}

La parte excavada de la plataforma artificial se presenta como un basamento tronco piramidal de base rectangular con un área estimada de $26,5 \times 13 \mathrm{~m}$, de $21 \times 8,75$ $\mathrm{m}$ en su cima y un $1 \mathrm{~m}$ de altura (figs. 6 y 7). Está construida de tierra compactada con ligeras variaciones en su coloración y densidad (fig. 8). Los elementos de contención del terreno en talud de sus vertientes $\mathrm{N}$ y E están reforzados con adobes sueltos marcando la pendiente (fig. 9) y cubiertos de una capa de quincha cocida. Sobre la vertiente $\mathrm{S}$ se levanta uno de los muros de cerramiento, que cumple también la función de contención de este lado de la plataforma. Como hemos dicho anteriormente aún no se ha localizado la vertiente $\mathrm{W}$.

Mención aparte merece el talud E, ya que su función aparentemente va más allá

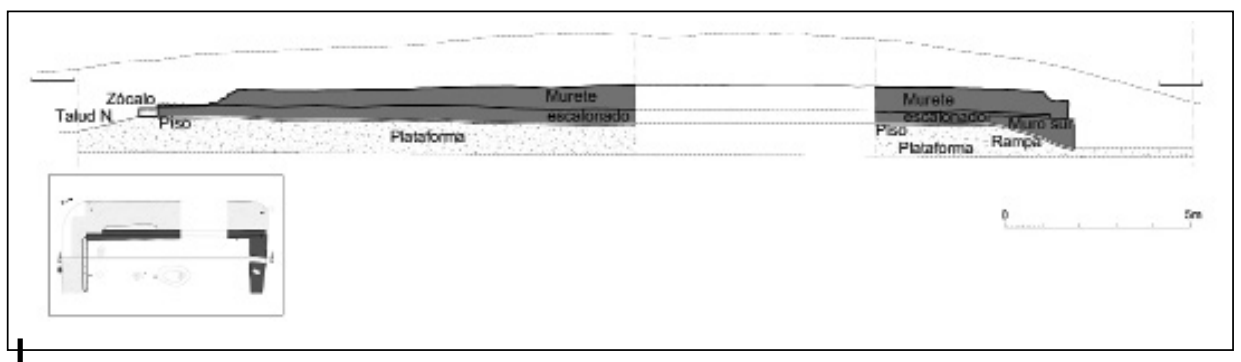

Figura 7 - Sección N/S de la Estructura 1 del montículo J8

Dibujo: N. Simonelli. Original: M. Guinea

de la contención del terreno. Una vez sobrepasado el grosor de la plataforma, continúa hasta la cabecera del murete escalonado cubriendo su paramento $\mathrm{E}$, lo que le da una altura de 1,93 m con un gradiente medio de $30^{\circ}$ (figs. 4, 10, 11). En las catas se ha podido observar que en su construcción interviene una tierra muy compacta y estéril de color amarillo fuerte, reforzada por adobes sueltos, que se concentran en algunos lugares, como pudo comprobarse en la esquina NE (fig. 9b) donde se agrupan en diferentes tamaños y materiales9. Está totalmente

9 Los más frecuentes parecen ser los de barro gris arcilloso de granulometría fina y forma paralelepípeda, bien con planta y sección rectangular de esquinas redondeadas $(30 \times 18 \times 7 \mathrm{~cm}) \mathrm{o}$ con planta cuadrada de esquinas redondeadas y sección rectangular de esquinas redondeadas (29 $x 27 \times 7,5)$, pero también hay de barro amarillento y de quincha similares a los del murete. 
Manabí, Ecuador: la estructura 1 del montículo J8 del sitio manteño de Japoto

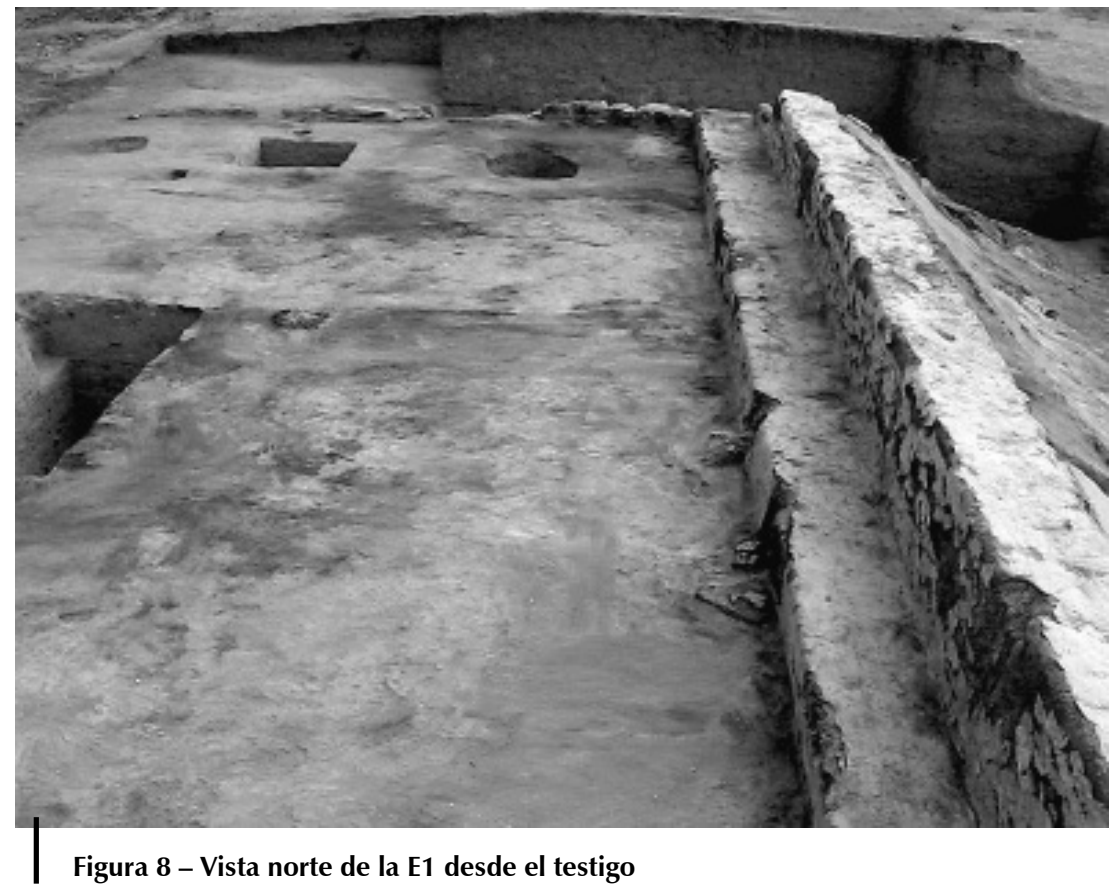

Desde este ángulo se aprecia el murete escalonado y la tierra compactada de la plataforma. Foto: M. Guinea

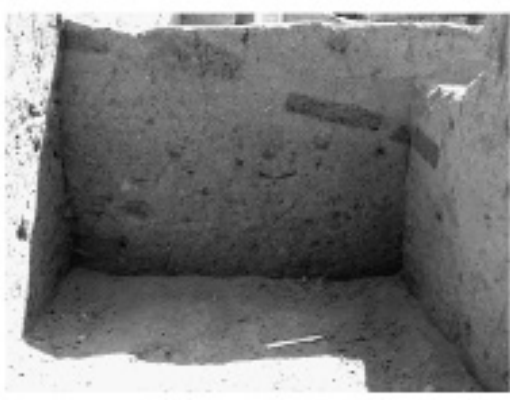

A

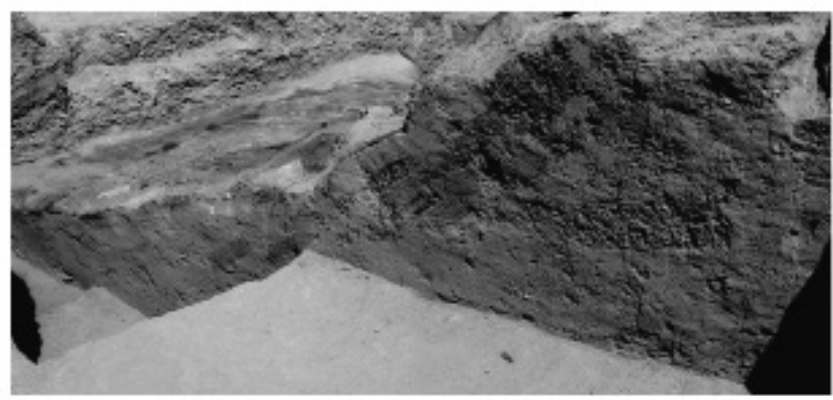

B

Figura 9 - Adobes de refuerzo en los elementos de contención de la plataforma. A) Talud Norte. B) Talud Este

Foto: M. Guinea 


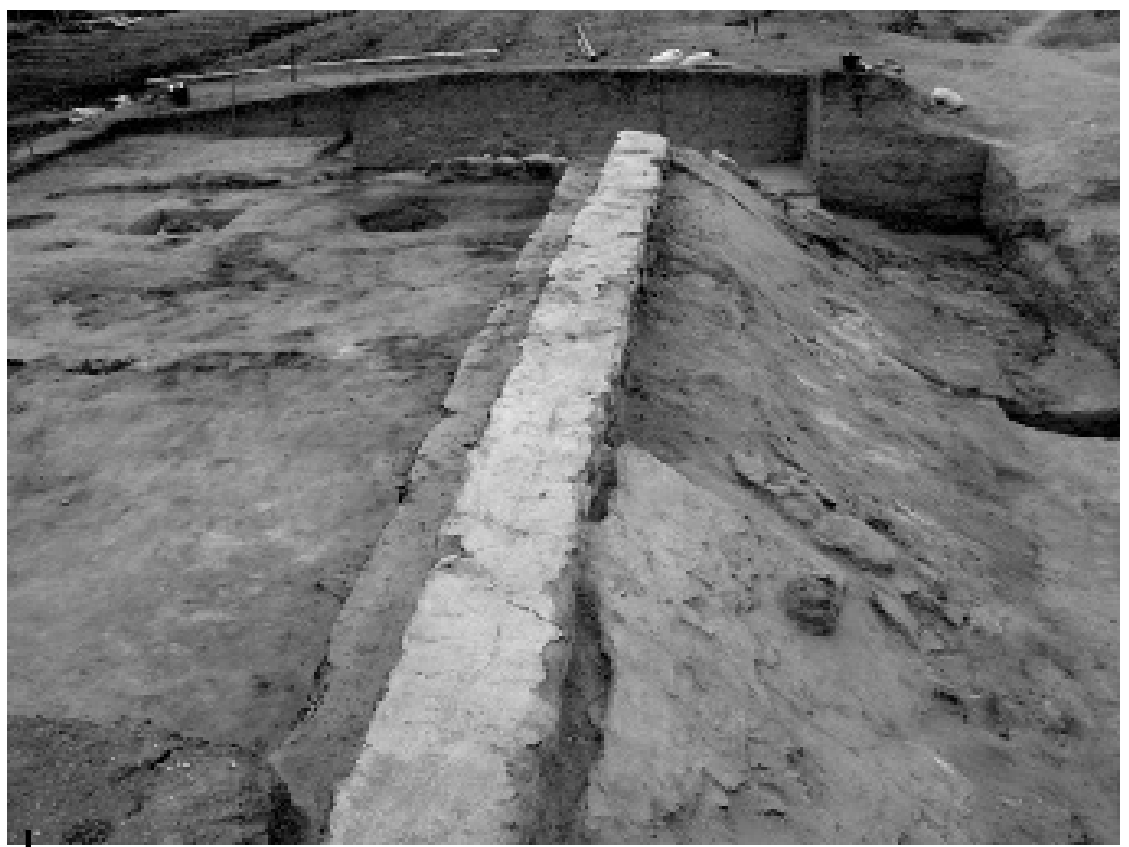

Figura 10 - Vista norte de la Estructura 1 desde el testigo

En primer plano el Talud Este roto. Al fondo, bajo el piso, una vasija enterrada (R5). Foto: M. Guinea

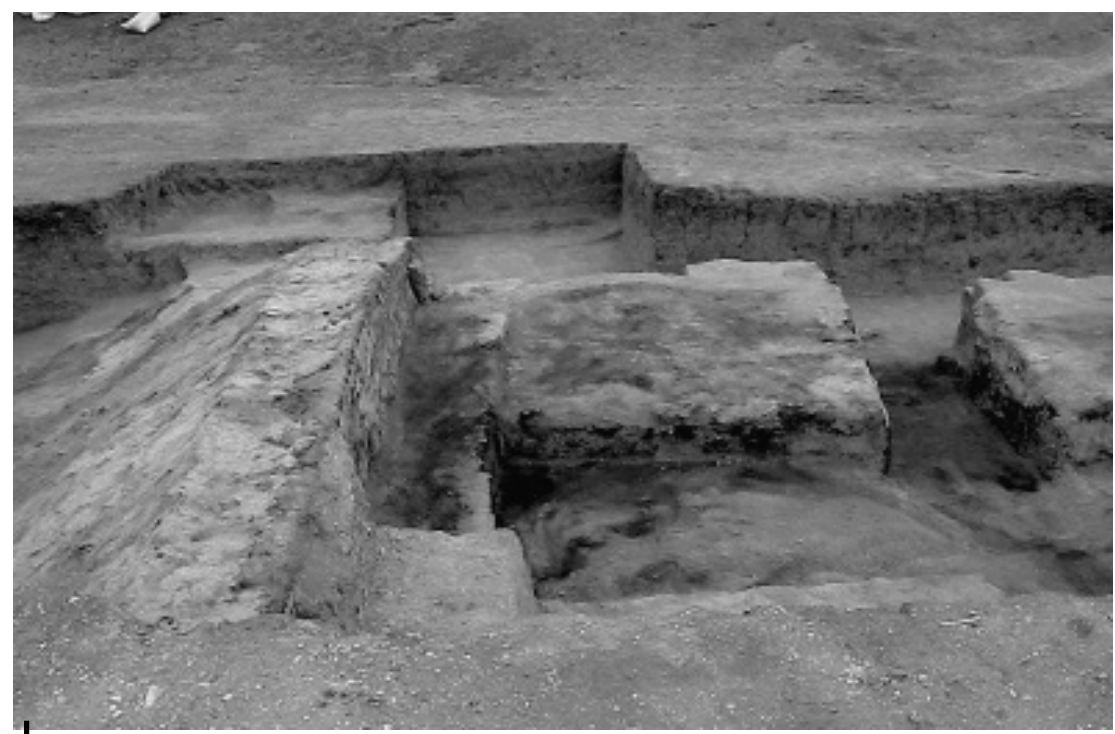

\section{Figura 11 - Vista sur de la E1 desde el testigo}

Se observan el Talud E llegando hasta la cabecera del murete y el vano que corta el muro sur. Foto: M. Guinea 
cubierto por una gruesa capa de quincha cocida de $9 \mathrm{~cm}$ de espesor que, en el primer 1,5 m de su parte superior, está recubierta con un fino enlucido en blanco preparado con diversos minerales, arcillas, carbonato de calcio y una cola proteínica (ver Wright en este mismo volumen). Su longitud actual N/S es de 24 $\mathrm{m}$, aunque sería algo mayor ya que está roto en ambos extremos. A 2,5 m de la esquina $\mathrm{N}$ del murete escalonado, tiene una amplia rotura en su parte superior de $6,5 \mathrm{~m}$ de largo y una anchura y profundidad medias de $60 \mathrm{~cm}$ (fig. 10). Hueco, en el que, como hemos dicho más arriba, pudo encajarse algún otro elemento arquitectónico. La rotura continúa, con una anchura de $10 \mathrm{~cm}$, al menos otros 2,5 $\mathrm{m}$ hacia al sur hasta llegar al testigo, pasado el cual el talud aparece completo (fig. 11). Un nivel irregular de maderas y cañas quemadas, de mayor entidad en sus extremos, cubría toda la superficie del talud, incluidas las roturas. El incendio fue tan fuerte que la cubierta de quincha está prácticamente calcinada en su base. El talud N no está tan definido (figs. 6, 7, 9b); parece que los adobes de refuerzo fueran menos numerosos y la capa de quincha que lo recubre es de tan solo unos $3 \mathrm{~cm}$. Su altura va disminuyendo en dirección $\mathrm{W}$ desde los 1,93 $\mathrm{m}$ de la esquina NE hasta los $66 \mathrm{~cm}$ de su entronque con el nivel superior de lo que venimos llamando plataforma del montículo J8.

Es posible que el sistema constructivo incluyera algunos hitos de referencia para la delimitación de los volúmenes: en la esquina NE del recinto, por debajo del piso y justo en la confluencia del zócalo de la pared con el murete, se encuentra la huella de una larga caña (fig. 5, R9) de 1,60 m de altura y $18 \mathrm{~cm}$ de diámetro. En esta misma localización, a 1,17 m bajo el piso, también se encuentra un adobe aislado. Igualmente $90 \mathrm{~cm}$ debajo del piso, se conserva otro poste de caña de $16 \mathrm{~cm}$ de diámetro (fig. 5, R8), en línea con una serie de hoyos realizados en el piso.

\section{2. 2. Muros}

Un murete escalonado delimita el recinto por el E (figs. 4, 6, 8). Su parte superior está rota en ambos extremos, $2 \mathrm{~m}$ en el $\mathrm{N}$ y $1 \mathrm{~m}$ en el $\mathrm{S}$, pero tendría un largo de 22,75 m. Tiene $91 \mathrm{~cm}$ de alto y 1,10 m de ancho. Lo conforman dos escalones, algo desiguales, aparejados con cinco hiladas dobles de adobes a soga, aparentemente sin mortero, apoyados sobre una base de tierra amarilla compactada, recubiertos de una gruesa capa de quincha cocida de espesor variable, con una media entre 2 y $3 \mathrm{~cm}$. Los adobes son paralelepípedos con bordes redondeados y están modelados a mano con una quincha gris10. Los que están a la vista como consecuencia de la rotura citada del talud E tienen ligeramente cocida su superficie exterior como resultado del incendio de la estructura. El primer escalón tiene su hilada inicial de adobes por debajo del piso, a consecuencia de lo cual su altura

10 Hay dos clases de adobes de quincha (barro gris arcilloso de granulometría fina mezclado con paja), ambos de forma paralelepípeda. Unos de planta ovalada y sección redonda y otros de planta y sección rectangular con esquinas redondeadas.

Medidas: Largo medio, $40 \mathrm{~cm}$ (30/44). Ancho medio $20 \mathrm{~cm}$ (16/23). Grosor medio $14 \mathrm{~cm}$ (12/15). Se puede ver su composición mineralógica en Wright, en este mismo volumen. 
aparente, 35-37 cm, es algo más baja que la del segundo, 55-60 cm, lo que le da un aspecto, y posible función, de banqueta corrida. Por su parte, el segundo escalón es ligeramente más estrecho, entre 52 y 56 cm y lleva el mismo enlucido blanco que el talud E. Ambos escalones han sido revocados con finas capas de quincha y enlucidos al menos en dos ocasiones, dedicando un mayor cuidado a la cabecera del murete. En la superposición de dichas capas se puede confirmar que estas fueron cocidas después de aplicarse.

El muro de cerramiento de la estructura por el S es muy diferente (figs. 6, 11). Tiene $2 \mathrm{~m}$ de ancho. Su altura sobre el piso del recinto es solo de $22 \mathrm{~cm}$ pero se levanta $75 \mathrm{~cm}$ desde la base de la plataforma, sobre cuya vertiente $\mathrm{S}$ descansa. Su sistema constructivo no está todavía completamente determinado, pero en su extremo W se observan zonas de aparejo de adobes a soga y tizón con un ligero mortero. Está, al igual que el anterior, todo cubierto de una capa de quincha cocida. A $2 \mathrm{~m}$ de la confluencia de este muro con el primer escalón del murete escalonado, se abre un acceso en rampa de $85-75 \mathrm{~cm}$ de ancho con una pendiente de $17^{\circ}$. El piso de este vano es igual al del recinto y aparece igualmente cubierto de una espesa capa de cenizas de más de $5 \mathrm{~cm}$ de espesor. Aunque la estructura es aparentemente abierta en todo su lado $\mathrm{W}$, parece que una de las funciones principales de este muro es marcar esta entrada por el Sur.

\section{2. 3. Pared}

Cerrando el recinto por el $\mathrm{N}$, se levantaba un pared de quincha de 6,5 $\mathrm{m}$ de largo y altura desconocida, con una estructura vertical de caña rolliza (Guadua angustifolia, Kunth) cada metro y un entramado de caña picada11 enquinchada por ambos lados, a cuyo paramento exterior se adosaba un zócalo de 6,90 m de largo, que se conservaba in situ, con el fin de preservar la base de la pared de salpicadura de lluvias y agua por capilaridad (figs. 7, 5, 12). El zócalo, que se conserva in situ, no tiene un sistema constructivo homogéneo, su mitad $\mathrm{N}$ está construida con una alineación irregular de adobes de ceniza volcánica cubiertos de una gruesa capa de quincha moldeada hasta alcanzar la altura y el grosor deseado $(25 \times 50 \mathrm{~cm})$. Esta altura se va reduciendo hasta casi desaparecer en la mitad S, donde los adobes son de quincha, más ocasionales y están cubiertos simplemente de tierra compactada, asemejándose al sistema constructivo del talud de contención. En él se marcan alineadas las huellas de 7 cañas rollizas de un tamaño medio de $9 \mathrm{~cm}(7-10 \mathrm{~cm}), 5$ por el interior clavadas en el piso y 2 en la cabecera. Algunas conservan restos de las cañas quemadas.

La pared apareció caída sobre el piso (figs. 5, R14, 12), pegada al zócalo, cubriendo un área continua de $14,5 \mathrm{~m}^{2}$. Entre ella y el piso había una capa de cenizas, entre 5 y $10 \mathrm{~cm}$ de espesor, resultado de la combustión de madera y cañas, que con toda probabilidad pertenecieron a la techumbre. La evidencia se presentó

11 Las cañas picadas debieron de estar sujetas con algún tipo de fibra (sapan o bejucos) a la cañas rollizas verticales, antes de ser recubiertas con la quincha. 


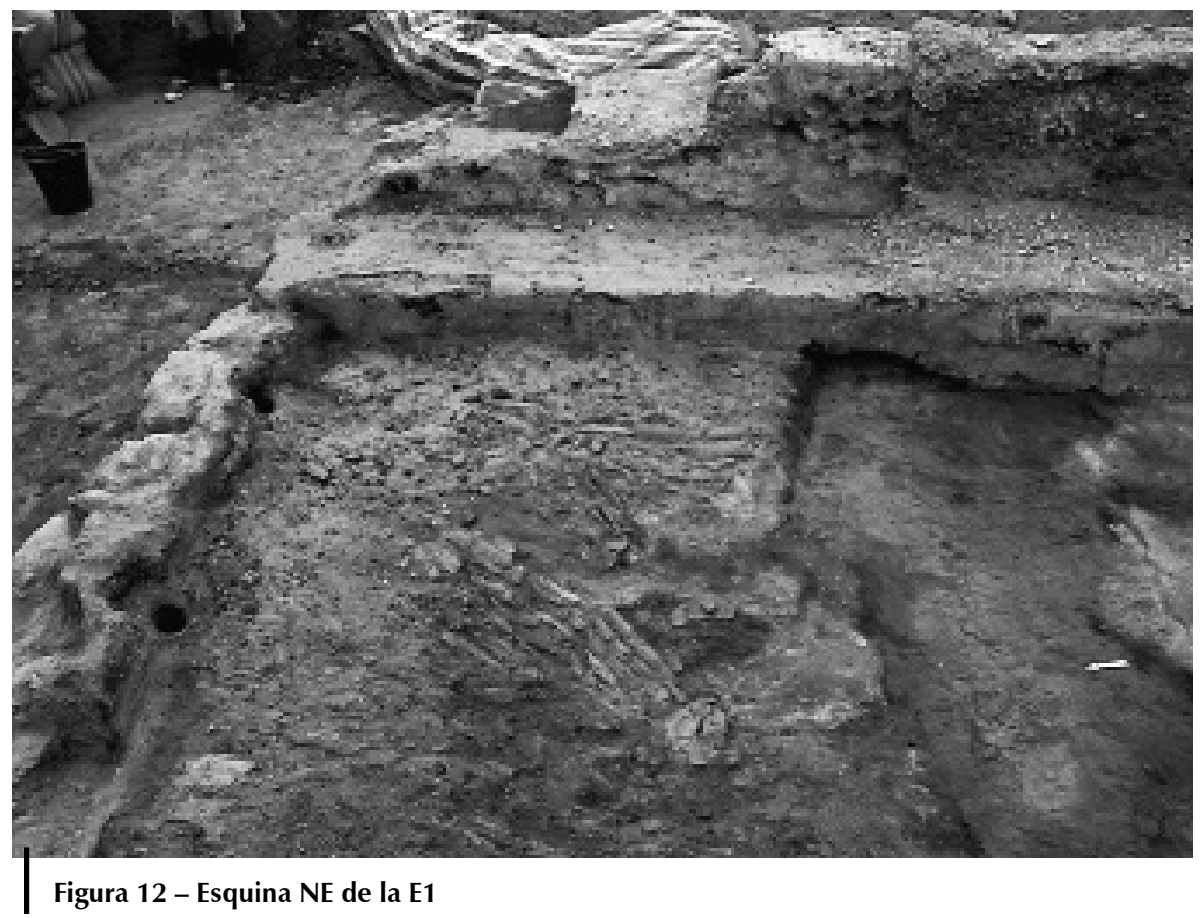

Se aprecian la pared de quincha sobre el piso, el zócalo y algunos de los huecos de la estructura vertical. Foto: M Guinea

en forma de fragmentos de quincha quemada con la huella de la caña picada, cuyos restos calcinados de conservaban en muchos de ellos. Pudiera haber sido empujada hacia adentro del recinto, ya que no se recogió ningún fragmento sobre el zócalo ni sobre el talud, apreciándose en el murete escalonado la marca que hicieron las maderas y cañas ardientes al ser desplazadas por la pared. Aunque es difícil establecer su comportamiento en la caída, su aspecto sobre el piso sugiere una fuerte inclinación en borde $\mathrm{W}$ y la posible existencia de un vano en la parte alta de su mitad $\mathrm{E}$.

\section{2. 4. Piso}

Todo el espacio interior del recinto está cubierto por un piso de quincha de un espesor promedio de $5 \mathrm{~cm}$ (figs. 4, 10, 8). La quincha está cocida los primeros $5,75 \mathrm{~m}$ desde el murete escalonado hacia el $\mathrm{W}$, a partir de donde continúa dos metros más como una capa más fina compacta ennegrecida y discontinua. Bajo el piso encontramos la tierra amarillenta, muy compacta y estéril de plataforma (fig. 8). En su superficie se observan zonas requemadas y ennegrecidas por las distintas acumulaciones de cenizas $(5-10 \mathrm{~cm})$ procedentes del desplome de la techumbre ardiente que lo cubren en toda su extensión. Como los demás elementos arquitectónicos, este piso se ha mantenido gracias a la aplicación de 
nuevas capas de quincha al deteriorarse. Debajo de las cenizas, el suelo aparece limpio como si hubiera sido cuidadosamente barrido antes del incendio. En el se localizaron tres hoyos (fig. 5, R1, R2 y R3) rellenos con distintos materiales que detallaremos más adelante, ya que mantenemos la hipótesis de que fueron abiertos en relación con las actividades de abandono del edificio, y una gran hoguera (fig. 5, R20) cubriendo un área de 7,5 $\mathrm{m}^{2}$ que es la única evidencia de actividad observada sobre el piso.

Pisos de quincha o arcilla cocidas se encontraron en otros sitios arqueológicos de la costa. En el mismo Japoto, toda la superficie de la cima del montículo (J5) estuvo cubierta por un piso de quincha cocida, sin arquitectura asociada. Estrada (1962: 26) encontró también varios pisos de barro rojizo compactado con paja asociados a cerámica manteña en el Corral B del cercano sitio de Chirije. Saville (1910: 36) señaló dos suelos de arcilla cocida en el montículo 2 de Cerro Jaboncillo y Marcos (1981: 58) localizó pisos de arcilla cocida en los montículos ceremoniales de La Loma de los Cangrejitos.

\section{2. 5. Techumbre}

Con las evidencias recuperadas, no es posible reconstruir el aspecto de la techumbre que cubriría necesariamente el edificio debido a la naturaleza de sus materiales de construcción. Esta misma razón, junto al tamaño del edificio, nos permite aventurar que tendría una altura considerable y una fuerte inclinación. Únicamente tenemos evidencias de fragmentos de algunos de sus materiales de construcción, los cuales aparecen en ocasiones individualizados entre las cenizas que cubren el piso (cañas rollizas de $3 \mathrm{~cm}$ de ancho, caña picada y 3 maderos de unos $10 \mathrm{~cm}$ de ancho y más de $2 \mathrm{~m}$ de largo), e información muy parcial de la localización y naturaleza de los soportes (maderas duras y cañas). No quedan macrorestos de las hojas de palma que presumiblemente han cubierto e impermeabilizado la techumbre y que quizás puedan encontrarse en los análisis de las cenizas del piso. Hay que tener en cuenta que las paredes de quincha nunca tienen funciones portantes, sino solo de cerramiento.

El área del piso se ha excavado y limpiado con distinta intensidad en los diversos sectores de la Estructura 1, por lo que no tenemos una visión completa de las posibles huellas de los soportes de la techumbre. Los que han sido localizados (fig. 5) parecen alinearse en un eje W/E y otros dos N/S. La línea W/E es la más clara y corre paralela al zócalo de la pared $\mathrm{N}$. La forman un poste de madera dura carbonizada de $20 \mathrm{~cm}$ de diámetro (R6), dos huecos de cañas de 8 y $10 \mathrm{~cm}$ de diámetro (R18), y el hueco de otro poste de $25 \mathrm{~cm}$ de diámetro (R10). Estos tres puntos mantienen una separación entre sí de $4 \mathrm{~m}$. Si aceptamos la posibilidad de que la pared de quincha tuviera en su extremo $\mathrm{W}$ la fuerte inclinación a la que nos hemos referido más arriba, podemos plantear la hipótesis de que esta fuerte inclinación de la techumbre funcionara a modo de cerramiento del recinto por este lado, lo que estaría en consonancia con la existencia de un acceso de entrada cortando el muro sur y en consecuencia, habría que suponer una orientación N/S para el lado largo de la techumbre. 


\section{ACTIVIDADES RITUALES RELACIONADAS CON LA DEDICACIÓN, USO, ABANDONO Y ENTIERRO DE LA ESTRUCTURA 1}

No es posible una reconstrucción total de las actividades posiblemente relacionadas con la dedicación, uso, muerte ritual y desacralización de la Estructura 1, dada la diferencia en la intensidad de los trabajos en los distintos sectores, en muchos de los cuales, especialmente en el extremo sur, no ha terminado de levantarse la última capa de tapado con el fin de preservar en lo posible el recubrimiento de quincha. Por otra parte, la falta del tiempo ha obligado a posponer la excavación de la mayor parte de los hallazgos. No obstante, a pesar del carácter fragmentario de la información, tenemos un total de 14 depósitos susceptibles de ser resultado de actividades del tipo de las referidas con anterioridad. Los presento a continuación junto a una primera aproximación a su posible significado.

\section{1. Dedicación y uso}

Interpretamos como posiblemente relacionados con la dedicación, sacralización o recarga de poder de la estructura, los depósitos incorporados al relleno de la plataforma de edificio durante su construcción (fig. 5): una vasija de gran tamaño, posiblemente destinada a contener chicha, tres depósitos de restos de actividades de consumición de alimentos, el esqueleto de un animal no identificado y dos hogueras. En posible relación con la parafernalia del culto, solo tenemos una hoguera en el centro del recinto.

A $8 \mathrm{~cm}$ por debajo del piso, se encontró una gran vasija de factura ordinaria (figs. 5 R5 y 10), cuerpo globular, base apuntada y cuello divergente. Estaba completa, salvo parte del cuello y el borde que faltaba en su totalidad. Aunque fragmentada, conservaba su forma original, ya que fue cuidadosamente rellena con una tierra similar a la matriz de la plataforma. Se inclinaba ligeramente hacia el este y su base, $50 \mathrm{~cm}$ por debajo del piso, estaba calzada con algunos fragmentos de cerámica y piedras. Con respecto a su ubicación, es destacable que se encuentre alineada con los hoyos rituales a los que nos referiremos más adelante. Esto nos hizo pensar en un primer momento que pudiera haber sido enterrada en el mismo proceso de apertura de los hoyos, pero su ubicación en la estratigrafía indicaba que más bien fue colocada donde se encontró en el proceso de construcción de la plataforma. Sus características físicas la asemejan a lo que se conoce como vasija para chicha; si fuera así, podríamos pensar que formó parte de un acto ritual de consumición de ésta u otra bebida, junto, o no, con otros alimentos. Terminado el ritual, se continuó con la construcción de la plataforma dejando in situ la vasija dentro del relleno, si bien, previamente fue «sacrificada» rompiéndole el cuello. En el relleno de otro montículo (J7) del yacimiento, el único de carácter funerario, se localizó otra olla, algo más pequeña, conteniendo igualmente solo tierra de la propia matriz en la que se encontraba y sin ningún contexto. Por ello, no podemos dejar de lado la posibilidad de que estemos ante una tradición de entierro de cántaros como ritos propiciatorios y culto a los ancestros, similar a la que Shimada et al. 
(2004: 532) proponen para los entierros de cántaros que encuentran bajo el piso de la Plaza de los Peregrinos de Pachacamac.

En las esquinas NE y SE de la Estructura 1, en la base del talud reforzado de la plataforma, 5-7 cm por debajo del suelo quemado y ennegrecido por el incendio, se encuentran dos depósitos (fig. 5, R12 y 23) con restos de actividades relacionadas con la consumición de alimentos. Otro similar (fig. 5, R25) se localizó 1,25 cm por debajo del piso. hay que notar que, al igual que la vasija, se encuentra dentro de la línea N/S que forman los hoyos rituales. El contenido de estos tres depósitos rituales y otros semejantes (fig. 5, R21, R24 y R28) localizados sobre la superficie del edificio es muy similar: caracoles de agua dulce (Pomacea sp.12) en abundancia, caracoles de monte (Porphyrobaphe sp.), restos de pescados grandes en conexión anatómica, fragmentos grandes de vasijas manteñas, y algunas conchas marinas. Presentan algunas variaciones cuya valoración no es posible evaluar en estos momentos, ya que pueden ser debidas a diferencias en la información obtenida. El depósito R12, excavado en su totalidad, contiene también 36 cuentas discoidales de conchas blancas e, inmediatamente debajo, un fragmento de una bóveda craneana de un individuo adulto probablemente mascúlino (ver Delabarde en este mismo volumen). El R23 incluía varias empanadillas13; faltaban muchos datos para el R25 y poco más podíamos decir del depósito R13, no excavado, que se encuentraba en el interior del talud $\mathrm{N}$ de la plataforma a $160 \mathrm{~cm}$ de profundidad y mostraba un esqueleto articulado, o parte, de un animal grande no identificado.

Restos de festines especiales, generalmente enterrados en hoyos rituales, se han documentado en bastantes sitios arqueológicos del área andina, en los que junto con los desechos de alimentación se incluyen otros objetos y fragmentos grandes de vasijas o vasijas enteras rotas (Bruhns, 2004: 69-71). En el Ecuador las más antiguas de estas actividades se encuentran en la «Casa de Reuniones» de Real Alto (Marcos, 1988: 15-16) en el período Valdivia III (2300-2200 a. C.) y en el sitio formativo de Pirincay (1500 a. C.-100 d. C.) excavado por Bruhns (2004). Uno de los muchos ejemplos en el Perú se encuentra en el patio de la citada Plaza de los Peregrinos de Pachacamac (Shimada et al., 2004: 19-21), donde en una serie de hoyos cónicos se han depositado como ofrendas restos seleccionados de alimentación y fragmentos cerámicos no azarosos (fragmentos del cuerpo, bordes y cuellos) en un patrón que se repite por 300 años. En un contexto similar al que nos ocupa, el entierro ritual de un edificio en Cerro Lampay, Vega-Centeno (2007: 166-167) interpreta estos festines como rituales relacionados con la construcción del nuevo montículo que tapa el anterior.

12 Estos moluscos, llamados en el Ecuador caracoles dorados, forman parte de la alimentación de muchas poblaciones de América. Incluso en lugares como las sabanas de la amazonía boliviana, se criaron en tiempos prehispánicos (Erickson, 2000:191.

13 Porción de tierra comestible envuelta en una hoja, y sometida después a una ligera cocción u horneado, de las que se han recuperado más de quinientas en los distintos montículos del yacimiento de Japoto (Guinea, 2006a). 
Uno de los aspectos más reseñables de los depósitos de festines de la E1 de Japoto es la recurrencia en la aparición de conchas de caracoles de agua dulce en grandes cantidades, ya que no se encuentran con frecuencia en el yacimiento y parecen representar una comida especial. Una excepción es una acumulación de más de dos mil de estos ejemplares que se ha excavado en el montículo J4 en 2006 y que aparece igualmente junto a cortes articulados de restos de pescados grandes, y cerámica especial. La cantidad, calidad y concentración de estos restos nos lleva, en su momento a plantear la misma hipótesis de que fueran los restos de un festín. Es posible que estos caracoles y los de monte, que mueren en los periodos secos y cuyos huevos eclosionan en grandes cantidades cuando llegan las lluvias, tuvieran una significación simbólica relacionada con la muerte y la resurrección. En este aspecto, es interesante el hallazgo de Piana \& Marotze (1975: 209) en Agua Blanca de un pozo conteniendo un esqueleto «envuelto por completo en caracoles» (Porphyrobae sp.).

Con respecto a las dos hogueras dentro de la Estructura 1, tenemos muy poca información de una de ellas (fig. 15, R11), salvo su localización, a 1,80 m de profundidad, en el giro NE del talud de la plataforma y el aspecto consistente del fragmento de cenizas observable. Para el entendimiento de las características de la otra hoguera (fig. 6), es necesario presentarla junto a la evidencia de una tercera (fig. 5, R20) que se le superpone sobre el piso y es la única actividad reconocible de uso del edificio, como hemos dicho más arriba. Esta es una gran hoguera que produce muchas cenizas y pequeños carbones que cubren un área de $4 \times 2,5 \mathrm{~m}$ $\left(7,5 \mathrm{~m}^{2}\right)$ y que contiene en su interior un aglomerado $\left(2,2 \mathrm{~m}^{2}\right)$ compacto de cenizas volcánicas14, ocupando una posición central en el eje N/S de la estructura. No se observan restos macroscópicos de lo que se puede estar quemando o cocinando. El único material asociado es un fragmento cerámico perteneciente al cuerpo de una vasija grande de acabado ordinario. Una estructura de combustión similar se levanta en el mismo lugar al finalizar la construcción de la plataforma y antes de construir el piso, hecho que se puede observar en el corte de uno de los hoyos rituales (fig. 5, R3) que traspasa ambas hogueras. Es destacable que hogueras semejantes, en tamaño y materiales, se han encontrado en otro montículo (J3) del yacimiento, donde se repiten en el mismo lugar en tres de las últimas capas de relleno y elevación del montículo. Todas presentan, igualmente, un núcleo de blancas cenizas volcánicas cubierto de una primera capa de cenizas grises algo compactas 15 con inclusiones carbonosas y una segunda de capa de cenizas sueltas con muchos carbones. Debajo de las hogueras, siempre en su NE, se localiza un área de tierra rubificada en círculos de distinta intensidad y tamaños, igual que se observa en la hoguera por debajo del piso de la Estructura 1. Esto nos lleva a pensar que quizás la primera hoguera tiene lugar al finalizar el relleno de la plataforma, siguiendo un patrón marcado de conducta. La posición central de la hoguera que

${ }^{14}$ Identificación realizada por la vulcanóloga Silvia Vallejo del Instituto Geofísico, EPN Quito.

$15 \mathrm{El}$ análisis de la composición de esta capa, realizado por Nicole Platel en 2004, muestra que son cenizas de fogón endurecidas con una cimentación calcárea con algunas inclusiones de conchas calcinadas y pequeños gránulos de arcilla cocida. 
aparece sobre el piso puede estar marcando una significación especial para ella, aunque con los datos disponibles es difícil aventurar una interpretación. Puede ser un fuego ritual que forma parte de la parafernalia de las actividades en la E1, de lo que hay algunos indicadores, como su posición central, su repetición en la misma ubicación, su «muerte ritual» o puede ser el único objeto que no se ha retirado de la superficie del piso antes del incendio. Esta última circunstancia, sin embargo, sirve también para apoyar la hipótesis alternativa de que formara parte de las ceremonias relacionadas con su desacralización y abandono, cocinándose allí los alimentos de los festines cuya basura se ha depositado en las esquinas del talud.

\section{2. Desacralización y entierro}

Dentro de lo que es un patrón recurrente en los «entierros de templos», las actividades de terminación de uso incluyen la muerte ritual y desacralización del edificio previos. En el caso de la E1 parece ser que esto se lleva a cabo desmontando la arquitectura que se levanta por encima del murete escalonado ${ }^{16}$ y rompiendo sus esquinas $\mathrm{N}$ y $\mathrm{S} 17$, así como abriendo grandes hoyos en el muro sur (fig. 5, R4), el piso (fig. 5, R1 y R2) y la hoguera central (fig. 5, R3), que se ha rellenado de distintos materiales. Antes, después o a la vez se han depositado en distintos puntos de la estructura los restos de tres festines similares a los de dedicación (fig. 5, R14, R24, R28) y algunos restos óseos de un niño de corta edad (fig. 5, R26). Finalmente, el edificio ha sido «barrido» cuidadosamente, con las excepciones indicadas, e incendiado. El incendio ha sido tan intenso que ha llegado a calcinar completamente parte de la cubierta de quincha del talud E. La hipótesis de la intencionalidad del barrido e incendio se fundamenta en la frecuencia de esta conducta dentro de esta tradición de abandono y entierro de edificios sagrados en el área andina (Montoya, 2007: 200), su intensidad y regularidad, así como en la poca probabilidad de que el recinto resultara tan limpio si el fuego fuera casual. Una posible interpretación de los grandes hoyos que se abren en distintas localizaciones de la estructura es, como hemos dicho más arriba, que formaran parte de la destrucción ritual de los elementos arquitectónicos del edificio (piso y muro sur), aunque la diversidad de su contenido y localización apuntan a que pudieran tener otro tipo de significado no muy fácil de alcanzar. Todos tienen una sección troncocónica invertida y una planta subrectangular sobre el terreno que enseguida se redondea en torno a $1 \mathrm{~m}$ de diámetro, disminuyendo hasta unos $50 \mathrm{~cm}$ con la profundidad que alcanza en general los $50 \mathrm{~cm}$, salvo en el caso del uno de ellos (fig. 5, R1) que llega a $1 \mathrm{~m}$. Es precisamente este uno de los dos

16 El desmonte de la arquitectura fue en su mayor parte, al menos, previa al incendio, ya que sobre los huecos dejados por desmonte se encontraba el nivel de incendio. Parte de la esquina NE del murete escalonado pudo ser una excepción, siendo desmontada y colocada sobre el piso en el momento del tapado.

17 La destrucción de las esquinas fue muy intensa haciendo muy difícil la reconstrucción de esta parte del edificio. En la NE se observó una gran piedra arrojada sobre el talud. 
hoyos que más claramente aparecen relacionados con la destrucción del piso, muy estropeado en su inmediaciones. Contiene diversos materiales constructivos (madera descompuesta y grandes fragmentos de quincha cocida, algunos con aspecto de molduras e impronta de textiles) que pueden provenir de algunos elementos desmontados. Sus últimos $50 \mathrm{~cm}$ están rellenados con cascajo. El R4 (fig. 5) rompe el muro sur y su contenido es exclusivamente cascajo. De los dos restantes, uno (fig. 5, R2) solo contiene un fragmento de metate (isacrificado?) y ha sido colmatado por las cenizas de la techumbre y fragmentos de la pared caída; el otro (fig. 5, R3) traspasa la hoguera central sobre el piso, el piso y la hoguera bajo el piso siendo rellenado con un primer nivel de arena de playa $(16 \mathrm{~cm})$, un segundo de cenizas de carbón $(10 \mathrm{~cm})$ y finalmente $17 \mathrm{~cm}$ de cascajo. Aparentemente, todos estaban abiertos al comenzar el proceso de entierro $y$, casual o intencionalmente, su niveles superiores quedaron rellenos de cascajo, salvo en el caso de R2 que fue cubierto por el derrumbe de la pared de quincha, lo que indica que dicha pared se tumbó antes de comenzar a tapar con el cascajo. Su localización también apunta a una significación especial. Tres de ellos se encuentran alineados $\mathrm{N} / \mathrm{S}$ al final del piso cocido. En este mismo eje se encuentran la vasija enterrada y las hogueras. Por su parte el hoyo R2 con el metate se alinea $\mathrm{N} / \mathrm{S}$ con la rampa de entrada y E/W con la vasija enterrada.

Con respecto a los depósitos interpretables como correspondientes a ritos relacionados con el abandono del edificios hay tres restos de festines similares a los referidos con anterioridad (fig. 5, R14, R24, R28), aunque no han sido excavados completamente. El hecho de que la mayor parte de las conchas estén enteras, las vértebras de pescado articuladas y en su contexto estratigráfico, mezcladas con el nivel de incendio pero no quemadas, sugiere que estos alimentos se han consumido cerca o in situ y ha sucedido justo antes de que empezara la labor de tapado. Dos de los depósitos (R24 y R28) aparecen regados por el talud E de la plataforma, junto a las esquinas destruidas y en las proximidades de los festines de dedicación. El otro (R21) se ubica en la base del talud N, en el mismo eje N/S de los hoyos rituales. El depósito localizado en la esquina SE (R24) además de los restos alimenticios habituales y los grandes fragmentos cerámicos, incluye 56 cuentas automorfas (Oliva sp.) y un fragmento de maxilar humano con algunos dientes. El de la esquina NE (R28) también contiene una hemimandíbula izquierda con algunas piezas dentarias. Finalmente, y sin asociación de restos alimenticios, al pie del primer escalón del murete y a 1,5 m del muro sur, se han recogido una vértebra cervical, un cubito y una mandíbula con tres dientes de leche correspondientes a un niño de corta edad (fig. 5, R26)18.

El proceso de tapado, como sugiere la evidencia del hoyo ritual R2 citada más arriba, parece haber comenzado con el tumbado de la pared de quincha hacia dentro del recinto, apreciándose claramente en el murete escalonado la marca que hicieron las maderas y cañas ardientes que estaban sobre el piso, al ser desplazadas por la pared (fig. 12). No se puede descartar que se derrumbara sola, aunque si hubiera

18 Todos los restos humanos fueron identificados por la Dra. Tania Delabarde. 
sido así sería de esperar que hubieran aparecido restos de quincha sobre el murete escalonado y el zócalo, lo que no ocurrió. Después, la estructura fue cubierta (fig. 4) de cascajo procedente de un nivel del estero, un material seleccionado por sus características especialmente favorables para su buena conservación, mezclado con el cual se colocan sobre el piso, junto al muro sur y resbalando por el talud $\mathrm{E}$ partes de los elementos arquitectónicos desmontados, fundamentalmente adobes, pero también otros (fig. 5). Luego se añaden esporádicamente algunos más según se va formando el montículo hasta llegar a la capa de sellado. Finalmente, hay otra capa de cascajo más irregular, con la que creemos que termina el entierro y comienza la construcción del nuevo montículo. Es posible que todo el material de tapado, además de su selección por sus características físicas, haya sido preparado de forma ritual mezclando intencionalmente fragmentos cerámicos, ya que el cascajo del estero no los lleva y sí el de tapado.

\section{CONCLUSIÓN}

Aunque la E1 del montículo J8 de Japoto no ha sido todavía excavada en su totalidad, se han considerado de interés presentar un primer avance descriptivo de su arquitectura dada la singularidad que tiene dentro del yacimiento y de la arqueología de la costa ecuatoriana, donde hasta el momento no se conocen otras en la que los adobes formen parte de la arquitectura del edificio. Es destacable también la excelente conservación de sus materiales de construcción propiciada por su entierro. Queda aún mucho por hacer, entre otros, por ejemplo, la localización de los soportes de la techumbre o la determinación del su límite W. Ambos elementos son muy importantes, ya que el edificio estuviera o no abierto hacia esta orientación, puede afectar no solo la deambulación de las personas hacia y en su interior, sino también la visibilidad de las actividades que en el se realizaban. ¿La plataforma está exenta o adosada? ¿Directamente sobre el terreno o sobre otra plataforma mayor? ¿Qué otras estructuras están tapando el montículo J8? No obstante, la información obtenida, la excepcionalidad de los materiales de construcción, la ausencia de restos de actividades domésticas y el mismo entierro, me llevan a proponer, con todas las cautelas precisas, la hipótesis de una función ceremonial para la E1 y a considerar los contextos asociados recuperados en la excavación parte de su entierro ritual, considerándolo un ejemplo más de la amplia tradición andina de enterrar edificios de carácter sagrado.

\section{Agradecimientos}

Agradezco a María Ángeles Barriuso, Véronique Wright y Anne Rose de Fontainieu su imprescindible y dedicada colaboración en las tareas de excavación de la E1. Esta investigación ha sido parcialmente financiada por el Ministerio Español de Educación y Ciencia (TIN2005-08788-C04-04). 


\section{Referencias citadas}

BRUHNS, K., 2004 - Llamas y rituales en el Formativo Tardío de la sierra austral del Ecuador. In: Simbolismo y Ritual en los Andes Septentrionales (M. Guinea, ed.): 69-90; Quito: Editorial Complutense, Abya Yala.

DELABARDE, T., 2006 - Una secuencia de patrones funerarios manteños en la provincia de Manabí: primeros resultados de la tola J7, Sitio de Japotó (Ecuador). Bulletin de I'Institut Français d'Études Andines, 35 (3): 313-320.

ERICKSON, C. L., 2000 - An artificial landscape-scale fishery in the Bolivian Amazon. Nature, vol. 408 (9): 190 -191.

ESTRADA, E., 1957 - Prehistoria de Manabí, 82 pp.; Guayaquil: Publicación del Museo Victor Emilio Estrada, n. ${ }^{\circ} 3$.

ESTRADA, E., 1962 - Arqueología de Manabí Central, 205 pp.; Guayaquil: Publicación del Museo Victor Emilio Estrada, n. ${ }^{\circ} 7$.

FELDMAN, R., 1992 - Preceramic subsistence and Architecture Traditions. Andean Past, n. ${ }^{\circ}$ 3: $67-86$.

GUINEA, M., 2006a - El uso de tierras comestibles por los pueblos costeros del Periodo de Integración en los Andes Septentrionales. Bulletin de I'Institut Français d'Études Andines, 35 (3): 321-334.

GUINEA, M., 2006b - Un sistema de producción de cuentas de concha en un contexto doméstico manteño: Japoto (provincia de Manabí, Ecuador). Bulletin de l'Institut Français d'Études Andines, 35 (3): 299-312.

GUINEA, M., 2008 - Primer avance acerca del hallazgo de una estructura singular en las excavaciones del sitio de Japoto, Ecuador. Revista Española de Antropología Americana, vol. 38, n. ${ }^{\circ}$ 1: 257-264.

JIJÓN Y CAAMAÑO, J., 1997 [1952] - Antropología Prehispánica del Ecuador, 387 pp.; Quito: Museo Jacinto Jijón y Caamaño, Embajada de España, AECl, Editorial Santillana.

LUNNISS, R., 2007 - Venerando a los ancestros. La Evolución de un Centro Ceremonial del Formativo Tardío en Salango, Provincia de Manabí, Ecuador. In: Vida y costumbres de los pobladores del Ecuador Antiguo: 13-38; Guayaquil: Museo Presley Norton.

MARCOS, J., 1981 - Informe sobre el área ceremonial del complejo Manteño Huancavilca de la Loma de los Cangrejitos valle de Chanduy, Ecuador (ogsech 4). El Arquitecto, año 1, n. ${ }^{\circ}$ 5: 54-63; Quito.

MARCOS, J., 1988 - Real Alto. La historia de un centro ceremonial Valdivia, 344 pp.; Guayaquil: ESPOL, Corporación Editora Nacional.

McEVAN, C., 2003 - «And the sun sits his seat». Creating social order in andean culture, 629 рp.; Urbana-Champaing: University of Illinois. Microfilm Phd.

MONTOYA, M., 2007 - Arquitectura de la «Tradición Mito» en el valle medio del Santa: Sitio «El Silencio». Bulletin de l'Institut Français d'Études Andines, 36 (2): 199-220.

PIANA, L. \& MAROTZKE, L., 1975 - Las estructuras de Agua Blanca un complejo mantense. In: Unidad Cultural en el Litoral Meridional Ecuatoriano (L. Piana \& L. Marotzke eds.): 189-235; Guayaquil: Escuela Politécnica del Litoral.

SHADY, R. \& LÓPEZ, S., 2003 - Ritual de Enterramiento en Un Recinto en el Sector Residencial A en Caral-Supe. In: La Ciudad Sagrada de Caral-Supe: Los origénes de la Civilización Andina y la Formación del Estado Pristino en el Antiguo Perú (Shady \& Leiva, eds.): 187-206; Lima: Instituto Nacional de Cultura, Proyecto Especial Arqueológico Caral-Supe. 
SHIMADA, I., 1995 - Cultura Sicán. Dios, riqueza y poder en la Costa Norte de Perú, 219 pp.; Lima: Edubanco.

SHIMADA, I., SEGURA, R., ROSTWOROSWSKI, M. \& WATANABE, H., 2004 - Una nueva evaluación de la Plaza de los Peregrinos de Pachacamac. Bulletin de I'Institut Français d'Études Andines, 33 (3): 507-538.

STOTHERT, K., 2006 - La cerámica de etiqueta de las tolas de Japoto, costa de Ecuador Bulletin de l'Institut Français d'Études Andines, 35 (3): 265-283.

TOUCHARD, A., 2006 - Una casa manteña puede esconder otra: evaluación preliminar de la tola J6 de Japoto, provincia de Manabí, Ecuador. Bulletin de I'Institut Français d'Études Andines 35 (3): 285-298.

VEGA-CENTENO, R., 2005 - Ritual and architecture in a context of emergent complexity: a perspective from Cerro Lampay, a late archaic site in the central Andes, 397 pp. Tesis presentada a la Universidad de Arizona, EE. UU.

VEGA-CENTENO, R., 2007 - Construction, labor organization, and feasting during the Late Archaic Period in the Central Andes. Journal of Anthropological Archaeology, Vol. 26 (2): 150-171. 